\title{
Structural and biochemical insights into the homotypic PB1-PB1 complex between $\mathrm{PKC} \zeta$ and $\mathrm{p} 62$
}

\author{
REN Jun, WANG Jue, WANG ZhiXin \& WU JiaWei* \\ MOE Key Laboratory of Protein Science and Tsinghua-Peking Center for Life Sciences, School of Life Sciences, Tsinghua University, \\ Beijing 100084, China
}

Received October 17, 2013; accepted November 22, 2013; published online December 23, 2013

\begin{abstract}
The atypical PKC isoforms ( $\zeta$ and 1 ) play essential roles in regulating various cellular processes. Both the hetero-interaction between PKC $\zeta$ and p62 through their N-terminal PB1 domains and the homo-oligomerization of p62 via its PB1 domain are critical for the activation of NF- $\mathrm{KB}$ signaling; however, the molecular mechanisms concerning the formation and regulation of these homotypic complexes remain unclear. Here we determined the crystal structure of PKC $\zeta-\mathrm{PB} 1$ in complex with a monomeric p62-PB1 mutant, where the massive electrostatic interactions between the acidic OPCA motif of PKC $\zeta-\mathrm{PB} 1$ and the basic surface of p62-PB1, as well as additional hydrogen bonds, ensure the formation of a stable and specific complex. The $\mathrm{PKC} \zeta$-p62 interaction is interfered with the modification of a specific Cys of PKC $\zeta$ by the antiarthritis drug aurothiomalate, though all four cysteine residues in the $\mathrm{PKC} \zeta$-PB1 domain can be modified in in vitro assay. In addition, detailed structural and biochemical analyses demonstrate that the PB1 domains of aPKCs belong to the type I group, which can depolymerize the high-molecular-weight p62 aggregates into homo-oligomers of lower order. These data together unravel the molecular mechanisms of the homo- or hetero-interactions between $\mathrm{p} 62$ and $\mathrm{PKC} \zeta$ and provide the basis for designing inhibitors of NF- $\mathrm{\kappa B}$ signaling.
\end{abstract}

\section{PKC $\zeta$, p62, PB1 domain, heterodimerization and homo-oligomerization, aurothiomalate}

Citation: Ren J, Wang J, Wang ZX, Wu JW. Structural and biochemical insights into the homotypic PB1-PB1 complex between PKC $\zeta$ and p62. Sci China Life Sci, 2014, 57: 69-80, doi: 10.1007/s11427-013-4592-Z

The protein kinase $\mathrm{C}(\mathrm{PKC})$ family comprises a number of highly related serine/threonine kinases in mammals, which exert pivotal roles in many cellular processes and have been the focus of drug development in cancer, diabetic complications, heart failure and many other diseases [1-3]. Based on their cofactor requirements and sequence homology, these important kinases can be classified in three subfamilies: conventional (cPKC: $\alpha, \beta$ and $\gamma$ ), novel (nPKC: $\delta, \varepsilon, \eta$ and $\theta$ ), and atypical (aPKC: $\zeta$ and $1 / \lambda$ ) [4]. The cPKCs are activated by both diacylglycerol (DAG) and $\mathrm{Ca}^{2+}$, and each cPKC consists of an N-terminal autoinhibitory pseudosubstrate motif, a DAG binding $\mathrm{C} 1$ domain and a $\mathrm{Ca}^{2+}$ sensing

*Corresponding author (email: jiaweiwu@mail.tsinghua.edu.cn)
C2 domain followed by the catalytic kinase domain. The nPKCs resemble the cPKCs but are only activated by DAG because their $\mathrm{C} 2$ domains do not bind $\mathrm{Ca}^{2+}$. The aPKC subfamily is unresponsive to both DAG and $\mathrm{Ca}^{2+}$ due to the presence of an incomplete $\mathrm{C} 1$ domain and the lack of a $\mathrm{C} 2$ domain. Instead, the aPKCs are regulated by the PB1 (Phox and Bem1p) domain at their N-termini (Figure 1A), which is one of the protein-interacting modules that undergo homotypic domain-domain interactions and thus mediate a number of cellular signaling pathways [5-8].

The aPKC isoforms have been implicated in the regulation of many important signaling pathways such as NF- $\mathrm{KB}$ signaling, cell polarity pathway and MAPK/ERK cascade, where the PB1-mediated interactions between aPKCs and 
their interacting proteins including p62, Par-6 and MEK5 are essential for the biological functions of aPKCs $[9,10]$. The scaffold protein p62 is one of the well-characterized aPKC-interacting proteins, which is rich in proteininteracting domains/motifs consistent with its essential roles as a signaling hub in modulating cell survival, apoptosis, adipogenesis and autophagy [11-14]. The p62 protein also harbors an N-terminal PB1 domain (Figure 1A), and the PB1-PB1 interaction between aPKC and p62 ensures specificity and fidelity in the activation of NF- $\kappa B$ [15-17]. In addition, the PB1 domain of p62 facilitates its homo-oligomerization, which is also critical for its biological functions [18,19]. For instance, the PB1-mediated homo-oligomerization of p62, as well as its interaction with TRAF6 through the TRAF6-binding sequence, is required for the formation of p62-TRAF6 signaling hubs, the polyubiquitination of TRAF6 and the ultimate activation of NF- $\kappa$ B $[20,21]$.

Although the significance of the PB1-containing proteins, aPKCs and p62, in the regulation of NF- $\mathrm{KB}$ signaling and many cellular pathways has been well acknowledged, the molecular mechanism of homo- and/or hetero-interactions between two PB1 domains and its biological implication are elusive. In this study, we determined the complex structure of the PB1 domains of p62 and the atypical PKC $\zeta$. Although the interaction between $\mathrm{PKC} \zeta-\mathrm{PB} 1$ and p62-PB1 obeys the general property of $\mathrm{PB} 1-\mathrm{PB} 1$ interaction, our structure reveals an additional interacting site that ensures the specific recognition of $\mathrm{p} 62$ by $\mathrm{PKC} \zeta$. $\mathrm{PKC} \zeta$ depolymerizes p62 homo-oligomer by competing for the basic surface on the p62-PB1 domain that mediates self-association of p62. In addition, we found that the antirheumatoid gold compound aurothiomalate (ATM) can modify all four solvent-accessible thiol groups of $\mathrm{PKC} \zeta$-PB1, among which only Cys68 is located at the interface. Our biochemical analyses demonstrate that the ATM modification of Cys68 impedes the interaction between $\mathrm{PKC} \zeta-\mathrm{PB} 1$ and $\mathrm{p} 62-\mathrm{PB} 1$, which sheds light on the molecular mechanism of ATM in the cure of rheumatoid arthritis, a chronic inflammatory disease associated with NF- $\kappa \mathrm{B}$ activation.

\section{Materials and methods}

\subsection{Constructs, mutagenesis, and protein purification}

Plasmids of rat PKC $\zeta$ and human p62 were kindly provided by Dr. Wang HongRui (Xiamen University). The PB1 domains of PKC $\zeta$ (residues 12-101) and p62 (residues 1-102) were generated by standard PCR procedure and inserted into pACYCDuet-1 or pGEX-4T-2 vectors with N-terminal $\mathrm{His}_{6}$ or GST tag. The site-specific mutations of the PB1 domains were generated by PCR based site-directed mutagenesis and verified by sequencing. All proteins, overexpressed in E. coli BL21 (DE3) at $20^{\circ} \mathrm{C}$, were purified at $4^{\circ} \mathrm{C}$ over affinity columns (glutathione-Sepharose 4B, GE Healthcare, Pittsburgh, USA or Ni-NTA, Qiagen,Valencia, USA) and anion exchange columns (DEAE FF or Source 15Q, GE Healthcare), followed by size exclusion chromatography (Superdex 200, GE Healthcare). The PB1 complexes for crystallization trials were prepared by coexpression of GST-PKC $\zeta-P B 1$ and His $_{6}$-p62-PB1AM, and the GST tag was removed using human rhinovirus $3 \mathrm{C}$ protease before the ion exchange chromatography. All proteins were stored at $-80^{\circ} \mathrm{C}$.

\subsection{Plasmids, cell culture, transfection, and co-immuno- precipitation}

The pCMV-Myc-PKC $\zeta$, pCS2 $2^{+}$-Flag-p62 and their mutation/deletion constructs were generated according to standard molecular techniques, and the authenticities were confirmed by sequencing. HEK293T cells were maintained in DMEM medium (Invitrogen, Grand Island, USA) supplemented with $10 \%$ fetal bovine serum (HyClone, Waltham, USA), $100 \mu \mathrm{g} \mathrm{mL}^{-1}$ penicillin and $100 \mu \mathrm{gL}^{-1}$ streptomycin (Sigma-Aldrich, St. Louis, USA). Each indicated DNA was transfected into HEK293T cells seeded in a $35-\mathrm{mm}$ dish, using VigoFect (Vigorous, Beijing, China) according to the manufacturer's instructions. After $24 \mathrm{~h}$, cells were lysed in the lysis buffer containing $20 \mathrm{mmol} \mathrm{L}^{-1}$ Tris $(\mathrm{pH}$ 7.4), $150 \mathrm{mmol} \mathrm{L}^{-1} \mathrm{NaCl}, 0.5 \% \mathrm{NP}-40,25 \mathrm{mmol} \mathrm{L}^{-1} \mathrm{NaF}, 2$ mmol L ${ }^{-1} \mathrm{Na}_{3} \mathrm{VO}_{4}, 1 \mathrm{mmol} \mathrm{L}{ }^{-1}$ EDTA, $1 \mathrm{mmol} \mathrm{L}{ }^{-1}$ PMSF and one protease inhibitor cocktail tablet (Roche, Indianapolis, USA) per $50 \mathrm{~mL}$. The lysates were incubated at $4^{\circ} \mathrm{C}$ for $10 \mathrm{~min}$ and then centrifuged at $13000 \mathrm{r} \mathrm{min}^{-1}$ for $10 \mathrm{~min}$. The supernatants were immunoprecipitated with indicated antibody and protein A/G plus agarose (Santa Cruz Biotechnology, Dallas, USA) and rotated overnight at $4^{\circ} \mathrm{C}$. After spinning and washing for three times with the lysis buffer, the beads were mixed with SDS loading buffer, boiled, and subjected to SDS-PAGE. The samples were transferred to PVDF membranes (Millipore, Billerica, USA) and immunoblotted using anti-Myc (Santa Cruz Biotechnology) and anti-Flag (Sigma-Aldrich) antibodies, respectively.

\subsection{Gel filtration analysis}

Size exclusion chromatography using the Superdex 200 10/300 column on an ÄKTA FPLC (GE Healthcare) was carried out at $4^{\circ} \mathrm{C}$ to assess the apparent molecular weight of wild-type p62-PB1 and its mutants in solution and the interactions between p62-PB1 and PKC $\zeta-\mathrm{PB} 1$. The column was equilibrated with a buffer containing $50 \mathrm{mmol} \mathrm{L}^{-1}$ Tris (pH 8.0), $150 \mathrm{mmol} \mathrm{L}^{-1} \mathrm{NaCl}$ at a flow rate of $0.5 \mathrm{~mL} \mathrm{~min}^{-1}$ and calibrated with molecular mass standards. All protein samples or mixtures were diluted with the equilibration buffer to indicated concentrations and incubated on ice for $1 \mathrm{~h}$ to allow equilibrium to be reached. Each sample at a 
volume of $500 \mu \mathrm{L}$ was loaded to the Superdex column, and fractions of $0.5 \mathrm{~mL}$ each were collected. Aliquots of relevant fractions were subjected to SDS-PAGE, and proteins were visualized by Coomassie Blue staining.

\subsection{Crystallization, data collection, and structure de- termination}

Crystals of the complex between p62-PB1AM and $\mathrm{PKC} \zeta$-PB1 were grown using the hanging drop vapor diffusion method by mixing $2 \mu \mathrm{L}$ of the protein $\left(\sim 10 \mathrm{mg} \mathrm{mL}^{-1}\right)$ with $1 \mu \mathrm{L}$ of reservoir solution containing $0.1 \mathrm{~mol} \mathrm{~L}^{-1}$ Tris (pH 8.5), 8\% PEG 8000, $0.4 \mathrm{~mol} \mathrm{~L}{ }^{-1} \mathrm{MgCl}_{2}$, and $0.05 \mathrm{~mol}$ $\mathrm{L}^{-1}$ potassium sodium tartrate at $21^{\circ} \mathrm{C}$. Crystals were quickly transferred to a cryo-protectant buffer containing the reservoir solution supplemented with $20 \%$ (v/v) ethylene glycol and then flash-frozen under cold nitrogen stream at $100 \mathrm{~K}$. The diffraction data were collected at beamline 17U at Shanghai Synchrotron Radiation Facility and processed by the HKL-2000 package [22]. The structure was solved by molecular replacement using Phaser [23] with the structure of PKC1-Par6 $\alpha$ PB1 complex (PDB ID: $1 \mathrm{WMH}$ ) [24] as the search model. Standard refinement was performed with PHENIX [25] and Coot [26], and PROCHECK [27] was used to check the structure stereochemistry. The data processing and refinement statistics are summarized in Table 1, and the atomic coordinates and structure factors have been deposited in the PDB (http://www.pdb.org) under the accession code 4MJS. All structural representations in this paper were prepared with PyMOL (http://www.pymol.org).

\subsection{GST-mediated pull-down assay}

The recombinant GST-tagged $\mathrm{PKC} \zeta$-PB1 protein $(\sim 0.4 \mathrm{mg})$ was bound to glutathione-Sepharose $4 \mathrm{~B}$ resin $(0.2 \mathrm{~mL})$ pre-equilibrated with the buffer containing $50 \mathrm{mmol} \mathrm{L}^{-1}$ Tris ( $\mathrm{pH} 8.0$ ) and $150 \mathrm{mmol} \mathrm{L}^{-1} \mathrm{NaCl}$. To remove excess unbound GST-PKC $\zeta-\mathrm{PB} 1$ or other contaminants, the resin was washed three times with $1 \mathrm{~mL}$ buffer. Then, $\sim 0.4 \mathrm{mg}$ of His $_{6}$-tagged p62-PB1 was allowed to flow through the $\mathrm{PKC} \zeta-\mathrm{PB} 1-$ bound resin. After extensive washing, the bound proteins were eluted with $10 \mathrm{mmol} \mathrm{L}^{-1}$ reduced glutathione. All samples were subjected to SDS-PAGE, and proteins were visualized by Coomassie Blue staining.

\subsection{Modification of cysteine}

The recombinant $\mathrm{PKC} \zeta-\mathrm{PB} 1$ protein was mixed with 10-fold ATM in a buffer containing $50 \mathrm{mmol} \mathrm{L}^{-1}$ Tris $(\mathrm{pH}$ 7.4) and $150 \mathrm{mmol} \mathrm{L}^{-1} \mathrm{NaCl}$, and the mixture was incubated at $30^{\circ} \mathrm{C}$ for $15 \mathrm{~min}$. Excess ATM was removed by gel filtration. Both native and ATM-modified PKC $\zeta$-PB1 were subjected to modification by another thiol-reactive compound, the Ellman's reagent DTNB (5,5'-Dithiobis-(2-nitro- benzoic acid)).

Modification of the free thiol groups of PKC $\zeta-\mathrm{PB} 1$ by DTNB was carried out at $30^{\circ} \mathrm{C}$ in $1.8 \mathrm{~mL}$ reaction mixture containing $50 \mathrm{mmol} \mathrm{L}^{-1}$ Tris ( $\mathrm{pH} 8.1$ ), $150 \mathrm{mmol} \mathrm{L}^{-1} \mathrm{NaCl}$, $0.1 \mathrm{mmol} \mathrm{L}^{-1}$ EDTA and indicated amounts of DTNB and PKC $\zeta-P B 1$. Reactions were initiated by the addition of the $\mathrm{PKC} \zeta-\mathrm{PB} 1$ protein to the reaction mixture. Progress of the reaction was monitored continuously by following the generation of 2-mercapto-5-nitrobenzoic acid $\left(\mathrm{TNB}^{2-}\right)$ at $412 \mathrm{~nm}$ on a Lambda 45 spectrophotometer (PerkinElmer, Waltham, USA) equipped with a magnetic stirrer in the cuvette holder. The concentrations of available cysteine residues were calculated using an extinction coefficient for $\mathrm{TNB}^{2-}$ of $14140 \mathrm{~cm}^{-1} \mathrm{M}^{-1}$ at $412 \mathrm{~nm}$ [28].

\subsection{Isothermal titration calorimetry}

To assess the binding affinity between $\mathrm{PKC} \zeta$ and p62, we titrated p62-PB1AM into PKC $\zeta-\mathrm{PB} 1$ using ITC carried out at $25^{\circ} \mathrm{C}$ on a VP-ITC MicroCalorimeter (GE Healthcare). All proteins were prepared in a buffer containing $25 \mathrm{mmol}$ $\mathrm{L}^{-1}$ Hepes ( $\mathrm{pH} 7.4$ ) and $150 \mathrm{mmol} \mathrm{L}^{-1} \mathrm{NaCl}$. The sample cell was loaded with $1.43 \mathrm{~mL}$ of PKC $\zeta-P B 1\left(5 \mu \mathrm{mol} \mathrm{L}{ }^{-1}\right)$, and titration was carried out using a $284-\mu \mathrm{L}$ syringe filled with p62-PB1AM $\left(50 \mu \mathrm{mol} \mathrm{L}{ }^{-1}\right)$. Each titration experiment consisted of 27 consecutive injections of $10-\mu \mathrm{L}$ volume and 20-s duration each, with a 5-min interval between injections. To correct for the heat effects of dilution and mixing, control experiments were performed in which p62-PB1AM was injected into an identical solution but without $\mathrm{PKC} \zeta-\mathrm{PB} 1$. To determine the binding affinity between two p62-PB1 domains, the p62-PB1BM mutant $\left(7 \mu \mathrm{mol} \mathrm{L}{ }^{-1}\right)$ was similarly titrated with p62-PB1AM $\left(50 \mu \mathrm{mol} \mathrm{L}{ }^{-1}\right)$. The calorimetric data were analyzed with a one-site binding model assuming a binding stoichiometry of $1: 1$ using ORIGIN software supplied with the instrument.

\section{Results and discussion}

\subsection{Both PB1 domains are indispensable for the inter- action between $\mathrm{p} 62$ and $\mathrm{PKC} \zeta$}

Both $\mathrm{PKC} \zeta$ and p62 are multidomain proteins, each containing a PB1 domain (Figure 1). To verify the p62-PKCל interaction, we first performed co-immunoprecipitation assays using ectopically expressed proteins. As shown in Figure $2 \mathrm{~A}$, the full-length $\mathrm{PKC} \zeta$ protein was co-immunoprecipitated by the full-length p62, whereas deletion of the PB1 domain of either PKC $\zeta$ or p62 resulted in failure to bind to the counterpart protein. These data suggest that the PB1 domains are indispensable for the p62-PKC $\zeta$ interaction. Then, we analyzed the direct interaction between the purified recombinant proteins of the isolated PB1 domains using gel filtration assays (Figure 2B and $\mathrm{C}$ ). The PB1 domains, each consisting of approximate 80 residues, are conserved 

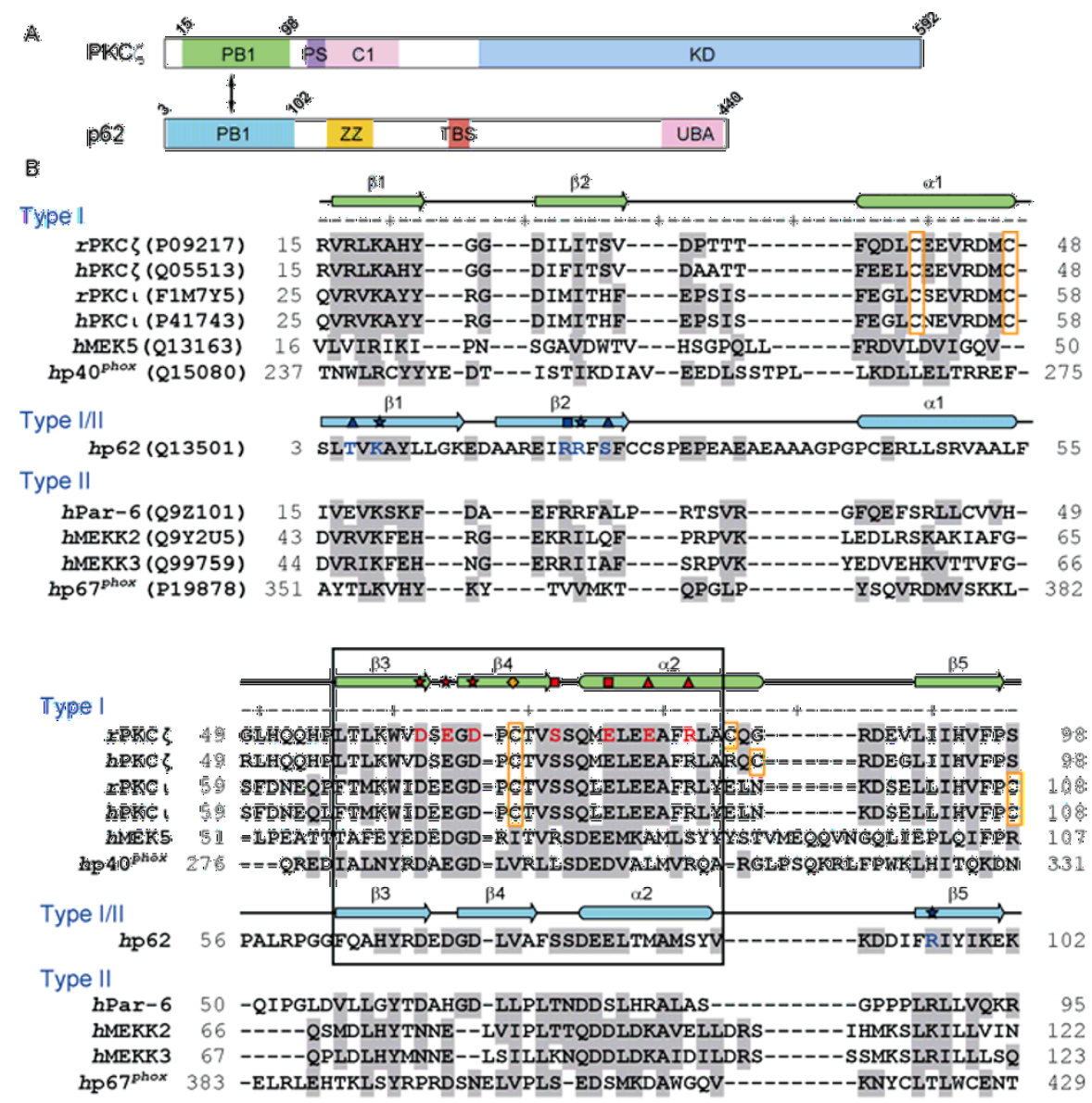

Figure 1 Functional domains/motifs of PKC $\zeta$ and p62. A, Schematic diagrams of rat PKC (Swiss-Prot ID: P09217) and human p62 (Q13501). PS, pseudosubstrate; KD, kinase domain; ZZ, ZZ-type zinc finger domain; TBS, TRAF6-binding sequence; UBA, ubiquitin associated domain. B, Sequence alignment of the PB1 domains of representative PB1-containing proteins from human and rat. The code following each protein name is the corresponding Swiss-Prot ID, and secondary structural elements of rat PKC $\zeta$-PB1 (green) and human p62-PB1 (cyan) are indicated above their sequences, respectively. The key residues at sites $\mathrm{A} 1, \mathrm{~A} 2$ and $\mathrm{A} 3$ of $\mathrm{PKC} \zeta-\mathrm{PB} 1$ are indicated by red asterisks, squares and triangles, respectively, and the interacting residues at sites B1, B2 and B3 of p62-PB1 are indicated by corresponding blue symbols. The OPCA motif conserved among type I and I/II PB1 domains and the cysteine residues of aPKCs are boxed, and the essential Cys within the OPCA motif is also indicated by orange diamond.

among fungi, plants and animals and can be grouped intothree types: type I, type II, and type I/II (Figures 1B) [29]. The type I group contains a conserved acidic motif (named the OPCA motif), while the type II group contains several lysine and/or arginine residues that form a basic surface opposite to the OPCA motif [10,30]. Therefore, the type I and type II PB1 domains can form heterodimers via electrostatic interactions [24,31,32]. The type I/II group contains both the OPCA motif and the basic surface, which enable the formation of homo-oligomers $[8,33]$. The PB1 domain of p62 (p62-PB1, residues 1-102) belongs to type I/II, and the wild-type recombinant p62-PB1 proteins indeed behave as high-molecular-weight aggregates, which makes the protein purification difficult (Figure 2B). Mutation of the highly conserved residues in the acidic motif (D69A/D71R, hereafter referred to as p62-PB1AM) or on the basic surface (p62-PB1BM, K7E/R96A) resulted in two monomeric p62-PB1 mutants [34]. When the p62-PB1AM mutant was mixed with equimolar amount of the PB1 domain from

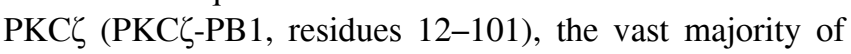

these two PB1 proteins co-migrated in earlier fractions, indicating the formation of a stable complex with $1: 1$ stoichiometry (Figure 2C). By contrast, the p62-PB1BM mutant does not interact with PKC $-\mathrm{PB} 1$ as reported [35]. We also examined the effect of the p62AM mutation on the interaction between two full-length proteins using the coimmunoprecipitation assay, and the result reaffirms that the p62AM mutant, engineered to destroy the acidic OPCA motif, does not abolish the binding of p62 to $\mathrm{PKC} \zeta$ (Figure $2 \mathrm{~A})$. Together, these results demonstrate that the N-terminal $\mathrm{PB} 1$ domains are necessary and sufficient for the $\mathrm{p} 62-\mathrm{PKC} \zeta$ interaction and that $\mathrm{p} 62-\mathrm{PB} 1$ provides the basic surface to interact with the acidic OPCA motif of $\mathrm{PKC} \zeta-\mathrm{PB} 1$.

\subsection{Overall structure of a heterodimeric complex be-

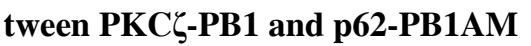

To unravel the molecular mechanism of the aPKC-p62 interaction, we carried out crystallization trials for complexes 


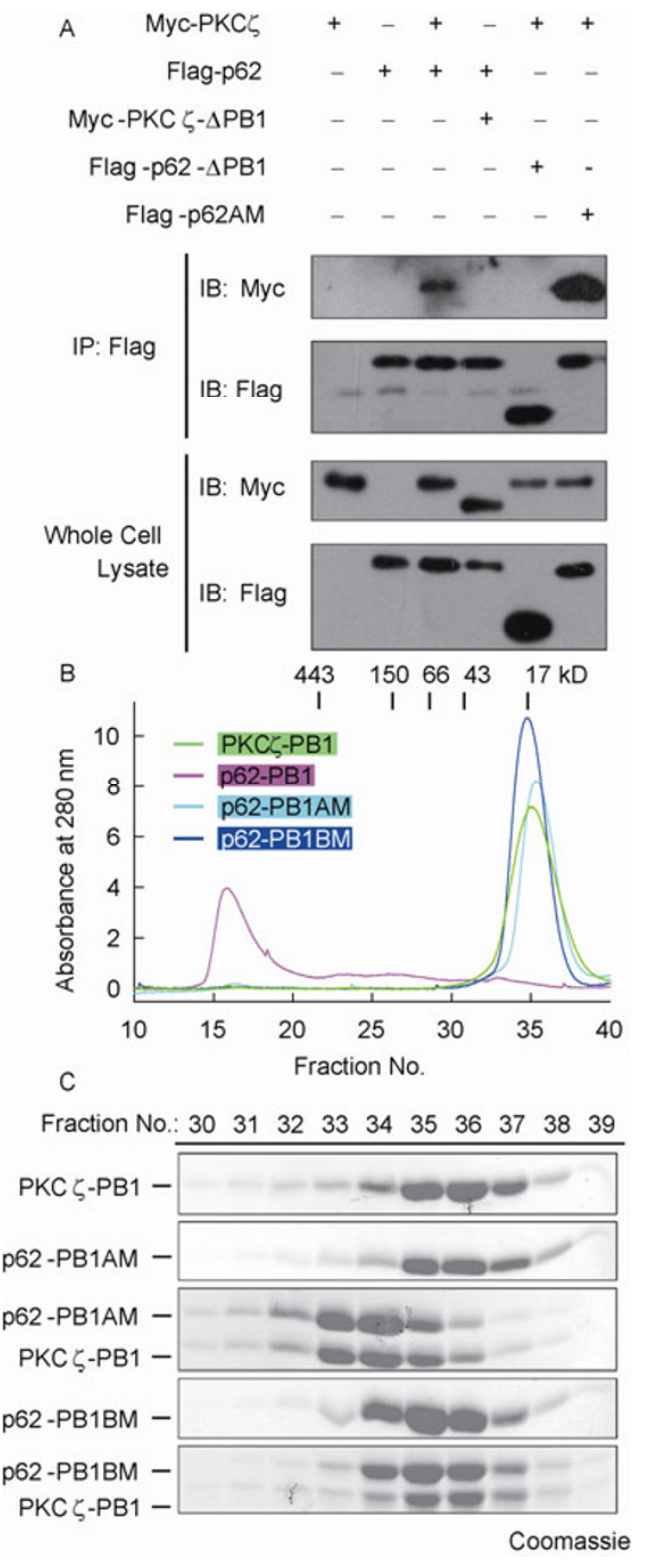

Figure 2 PKC $\zeta$ interacts with p62 through their PB1 domains. A, Co-immunoprecipitation (IP) assays for the interaction between $\mathrm{PKC} \zeta$ and p62. HEK293T cells were co-transfected with $2 \mu \mathrm{g}$ of Myc-PKC $\zeta$ and $1 \mu \mathrm{g}$ of Flag-p62 plasmids as indicated. Lysates were subjected to anti-Flag immunoprecipitation followed by anti-Myc immunoblotting (IB). B, Oligomerization states of $\mathrm{PKC} \zeta$-PB1 and wild-type or mutant p62-PB1. The size exclusion chromatography was performed to determine the apparent molecular weight of the PB1 domain/mutant at a concentration of $\sim 10$ $\mu \mathrm{mol} \mathrm{L}{ }^{-1}$. C, PKC $\zeta-\mathrm{PB} 1$ binds to the p62-PB1AM mutant with intact basic surface. PKC $\zeta$-PB1 $\left(50 \mu \mathrm{mol} \mathrm{L} \mathrm{L}^{-1}\right)$ was incubated with indicated p62PB1 mutant $\left(50 \mu \mathrm{mol} \mathrm{L}^{-1}\right)$, and the mixture was subjected to gel filtration analysis.

between $\mathrm{PKC} \zeta-\mathrm{PB} 1$ and $\mathrm{p} 62-\mathrm{PB} 1$. We purified the wild-type $\mathrm{PB} 1$ complex by coexpression of wild-type PKC $\zeta-P B 1$ and p62-PB1 in E. coli; however, all attempts to crystallize the wild-type complex were unsuccessful, likely due to heterogeneity of the p62 homo-oligomers. We turned to solve the structure of the $1: 1$ complex between $\mathrm{PKC} \zeta$ -
Table 1 Data collection and refinement statistics

\begin{tabular}{|c|c|}
\hline & PKC $\zeta$-p62 PB1 complex \\
\hline \multicolumn{2}{|l|}{ Data collection $^{\text {a) }}$} \\
\hline Space group & $P 2{ }_{1} 2_{1} 2_{1}$ \\
\hline \multicolumn{2}{|l|}{ Cell dimensions } \\
\hline$a, b, c(\AA)$ & $85.72,135.68,259.56$ \\
\hline$\alpha, \beta, \gamma\left(^{\circ}\right)$ & $90,90,90$ \\
\hline Resolution (§) & $40.00-2.50(2.59-2.50)^{\mathrm{b})}$ \\
\hline$R_{\text {merge }}$ & $0.086(0.519)$ \\
\hline$I / \sigma(I)$ & $22.6(4.1)$ \\
\hline Completeness (\%) & $100.0(100.0)$ \\
\hline Redundancy & $7.3(7.5)$ \\
\hline \multicolumn{2}{|l|}{ Refinement } \\
\hline Resolution $(\AA)$ & $39.53-2.50$ \\
\hline No. reflections & 105316 \\
\hline$R_{\text {work }} / R_{\text {free }}{ }^{\mathrm{c})}$ & $23.8 / 28.7$ \\
\hline \multicolumn{2}{|l|}{ No. atoms } \\
\hline Protein & 16410 \\
\hline Solvent & 397 \\
\hline \multicolumn{2}{|l|}{ B-factors $\left(\AA^{2}\right)$} \\
\hline Protein & 52.55 \\
\hline Solvent & 39.49 \\
\hline \multicolumn{2}{|l|}{ r.m.s. deviations } \\
\hline Bond lengths $(\AA)$ & 0.009 \\
\hline Bond angles $\left({ }^{\circ}\right)$ & 1.200 \\
\hline \multicolumn{2}{|l|}{ Ramachandran plot } \\
\hline Most favored & $1633(92.6 \%)$ \\
\hline Additionally allowed & $128(7.3 \%)$ \\
\hline Generously allowed & $3(0.2 \%)$ \\
\hline Disallowed & $0(0.0 \%)$ \\
\hline
\end{tabular}

a) All data sets were collected from a single crystal. b) Values in parentheses are for the highest resolution shell. c) $R_{\text {free }}$ was calculated on a random $5.0 \%$ reflections of the data.

PB1 and the p62-PB1AM mutant. Fortunately, we generated diffractable crystals and determined the complex structure to a resolution of $2.5 \AA$ (Figure $3 \mathrm{~A}$, Table 1 ). The crystal belongs to space group $P 2{ }_{1} 2_{1} 2_{1}$, and each asymmetric unit contains 12 identical p62-PKC $\zeta$ heterodimers. Both $\mathrm{PKC}$-PB1 and p62-PB1 in the complex structure display essentially the same topology as other PB1 domains, a ubiquitin-like $\beta$-grasp fold composed of one five-stranded $\beta$-sheet $(\beta 1-\beta 5)$ and two $\alpha$-helices $[24,29,30,32,33,35,36]$. The basic surface is mainly formed by the $\beta 1-\beta 2$ hairpin at the 'front' of the PB1 domain, whereas the acidic OPCA motif folds into the $\beta 3-\beta 4$ hairpin and helix $\alpha 2$ at the 'back' opposite to the basic side. The basic surface of p62-PB1 indeed interacts with the acidic OPCA motif of PKC in a front-to-back manner, resulting in the burial of approximate $1100 \AA^{2}$ exposed surface area (Figure $3 \mathrm{~A}$ ).

The structures of these two PB1 domains are readily superimposable to each other with an overall root-meansquare deviation of approximate $1.6 \AA$ over 60 core $C_{\alpha}$ atoms, and the major structural deviations were mapped to the $\alpha 2$ helix and some loop regions (Figure 3B). The NMR structures of the isolated PB1 domains of p62 (p62-PB1AM; 

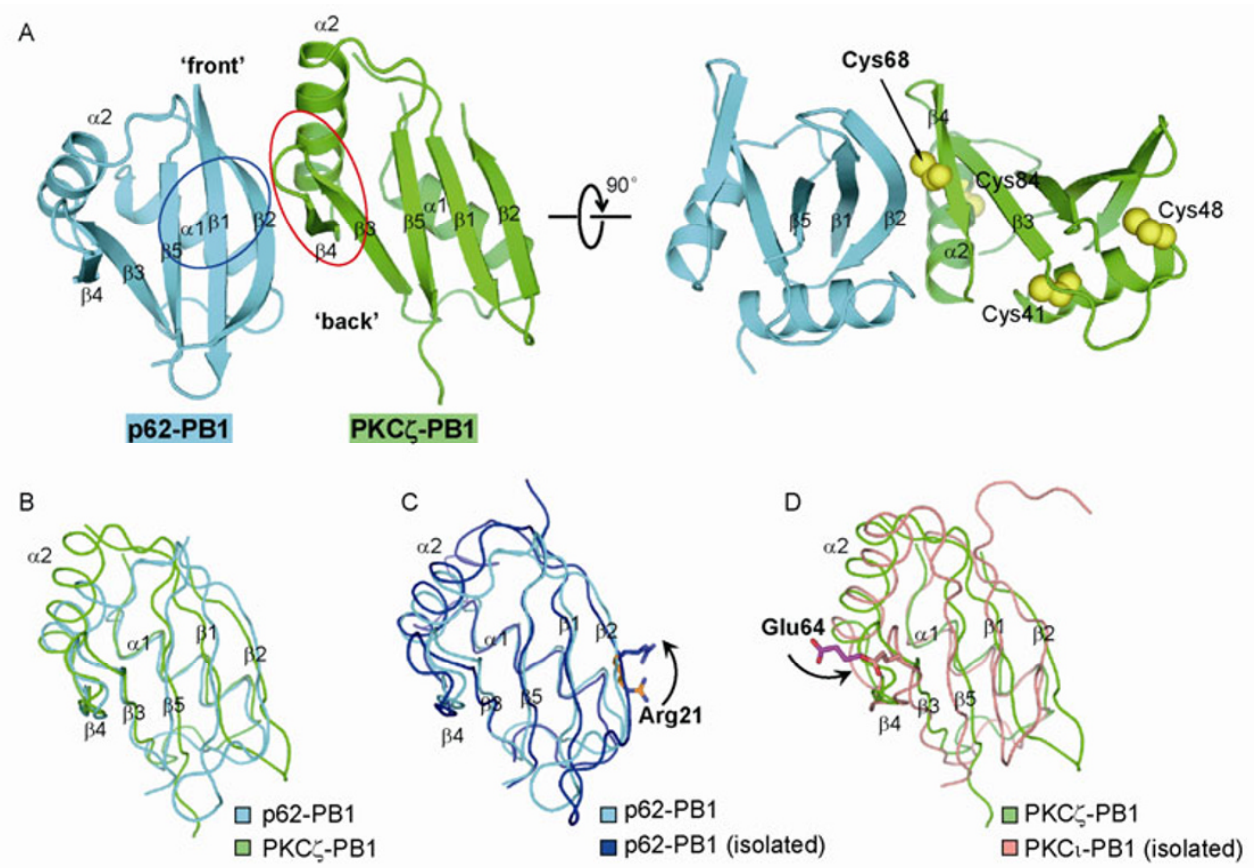

Figure 3 Crystal structure of p62-PKC $\zeta$ PB1 complex. A, Schematic representations of the complex between p62-PB1 (cyan) and PKC $\zeta-\mathrm{PB} 1$ (green) in two views related by a $90^{\circ}$ rotation around a horizontal axis. In the left panel, the interfaces on p62-PB1 and PKC $\zeta-\mathrm{PB} 1$ are circled in blue and red, respectively. In the right panel, all four Cys residues within $\mathrm{PKC} \zeta$-PB1 are shown in yellow spheres. B, Superposition of p62-PB1 (cyan) and PKC $\zeta-\mathrm{PB} 1$ (green) in the complex. C, Superposition of p62-PB1 (cyan) and the isolated p62-PB1 (blue, PDB ID: 2KKC). D, Superposition of PKC $\zeta-\mathrm{PB} 1$ (green) and the isolated $\mathrm{PKCl}$-PB1 (salmon, PDB ID: 1VD2).

PDB ID: 2KKC) and the other aPKC (PKC1-PB1; PDB ID: 1VD2) have been determined [33,35], and we respectively superimposed the p62-PB1 and $\mathrm{PKC} \zeta-\mathrm{PB} 1$ domains in our complex with these reported structures (Figure 3C and D). Their main chains exhibit little conformational differences, except some loop regions. However, the side chain of $\operatorname{Arg} 21$ on strand $\beta 2$ of p62-PB1 rotates approximately $45^{\circ}$ (Figure $3 \mathrm{C}$ ), and Glu64 at the $\beta 3-\beta 4$ loop of PKC (corresponding to Glu65 of PKC1-PB1) shifts $\sim 4 \AA$ and rotates $\sim 45^{\circ}$ (Figure 3D). In fact, upon the hetero-complex formation, many residues that are critical to the interactions between the p62-PB1 and aPKC-PB1 domains (see below) undergo subtle or even dramatic conformational changes.

\subsection{The electrostatic interactions play a dominant role in p62-PKC $\zeta$ complex formation}

A close-up view of the intermolecular interface of the p62-PKC $\zeta$ complex reveals that the interaction pattern resembles a three-pin plug, three functional clusters (A1-A3) within the OPCA motif of $\mathrm{PKC} \zeta-\mathrm{PB} 1$ interacting with three basic or hydrophilic regions (B1-B3) on the opposite surface of p62-PB1, respectively (Figure 4A). The most acidic $\mathrm{A} 1$ site of $\mathrm{PKC} \zeta-\mathrm{PB} 1$ is located at the $\beta 3-\beta 4$ hairpin, presenting three acidic residues Asp62, Glu64 and Asp66 (Figure 4B). This highly negative charged area is in close proximity to the prominent basic patch $\mathrm{B} 1$ of p62-PB1, which contains three positively charged side chains of Lys7,
Arg22 and Arg96 from strands $\beta 1, \beta 2$ and $\beta 5$. A total of six salt bridges are formed between the complementary A1 and B1 patches, which constitute the major interactions between PKC $\zeta_{-}$PB1 and p62-PB1. Specifically, Lys7 of p62-PB1, the most conserved and representative residue on the basic surface of type II and type I/II PB1 domains, forms three salt bridges with all of the three acidic residues at the $\mathrm{A} 1$ site of PKC 3 -PB1, and Arg22 and Arg96 in p62-PB1 respectively interact with Asp62 and Glu64 in PKC $\zeta-\mathrm{PB} 1$. The $\beta 2$ strand of p62-PB1 contains two consecutive Arg residues (Figure 1B), where the side chain of $A r g 21$ points to the opposite direction of $\operatorname{Arg} 22$ at site B1 and forms an additional positive electrostatic patch, B2 (Figure 4A and C). In $\mathrm{PKC} \zeta-\mathrm{PB} 1$, the $\mathrm{A} 2$ site consists of Ser71 and Glu75 at the $\beta 4-\alpha 2$ loop and the N-terminal turn of helix $\alpha 2$, and both side chains interact with Arg21 of p62-PB1. At the A3-B3 interface, Thr5 and Ser24 from strands $\beta 1$ and $\beta 2$ of p62-PB1 (B3) respectively form hydrogen bonds to Arg81 and Glu78 on helix $\alpha 2$ of PKC $\zeta-P B 1$ (A3), and the two PKCל residues form two additional intramolecular salt bridges, further stabilizing this interface (Figure 4D). Together, the electrostatic and hydrogen bond interactions at three paired sites of A1-B1, A2-B2 and A3-B3 within their PB1 domains lead to the formation of stable p62-PKC $\zeta$ complex. Structural inspections of the reported PB1 homoand hetero-dimers demonstrated that some cognate pairs display auxiliary interactions in addition to the conserved A1-B1 and A2-B2 sites [24,32]. Based on sequence analysis 
(Figure 1B), we believe that this additional A3-B3 interface plays a crucial role in the specific recognition between $\mathrm{p} 62$ and aPKCs.

To complement the structure analyses, we first generated a series of point mutations on $\mathrm{PKC} \zeta-\mathrm{PB} 1$ and examined their effect on the formation of p62-PKC $\zeta$ complex using GST-mediated pull-down assays. When p62-PB1AM was applied to the wild-type GST-PKC $\zeta-\mathrm{PB} 1$ preimmobilized to glutathione resin (Figure 4E, lane 1), these two PB1 domains formed a stable hetero-complex as resolved by SDS-PAGE. When the important acidic residues at sites A1 and $\mathrm{A} 2$ of $\mathrm{PKC} \zeta-\mathrm{PB} 1$ were individually replaced by Ala, the resulting $\mathrm{PKC} \zeta$ mutants (D62A, E64A, D66A and E75A) drastically abrogated the binding to p62-PB1AM (Figure
4E). By contrast, mutations of Ser71 at site A2 and both residues at site $\mathrm{A} 3$ displayed little effect on the hetero-complex formation. Residue Trp60 within the OPCA motif of $\mathrm{PKC} \zeta-\mathrm{PB} 1$ had been shown to mediate the homotypic PB1-PB1 interaction [18]. Although this residue is not directly involved in the PB1 complex formation, it participates in the hydrophobic core formation of the PB1 domain. Indeed, the W60A mutant impaired the interaction with p62-PB1, most likely due to disturbance of the integrity of PB1 domain (Figure 4E, lane 2). We next mutated the key interacting residues on the basic surface of PKC $\zeta-\mathrm{PB} 1 \mathrm{AM}$ and carried out pull-down assays with wild-type GSTPKCל-PB1 (Figure 4F). Substitutions of the basic residues Lys7, Arg21, Arg22 and Arg96 at both sites B1 and B2 of

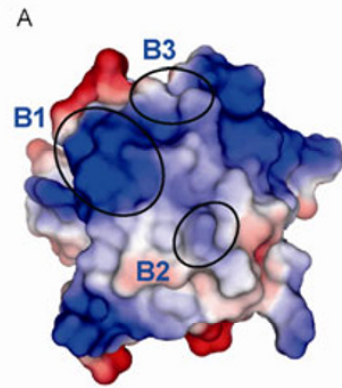

B

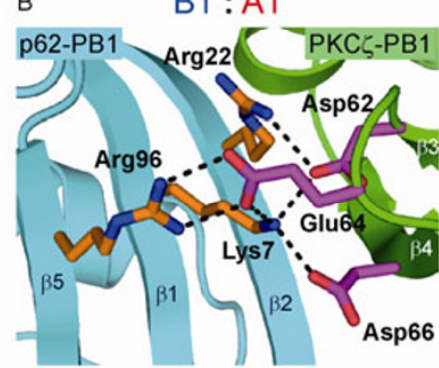

E

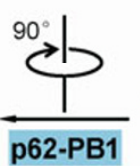

C

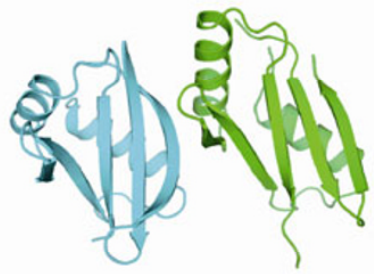

B2 : A2
p62-PB1

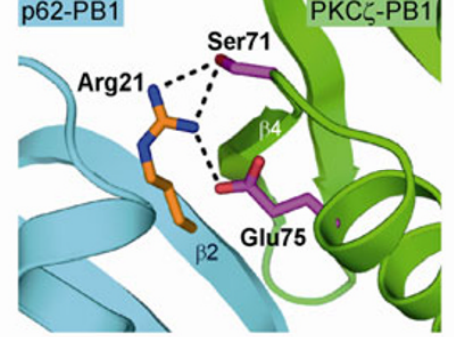

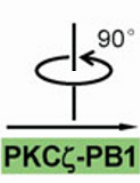

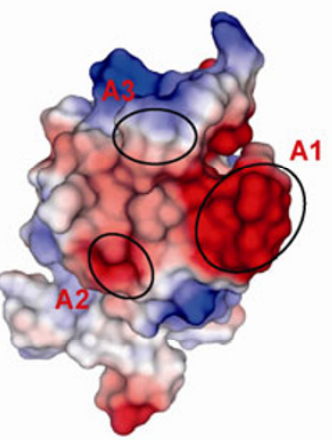

D

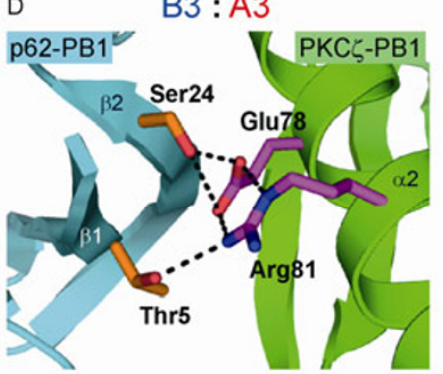

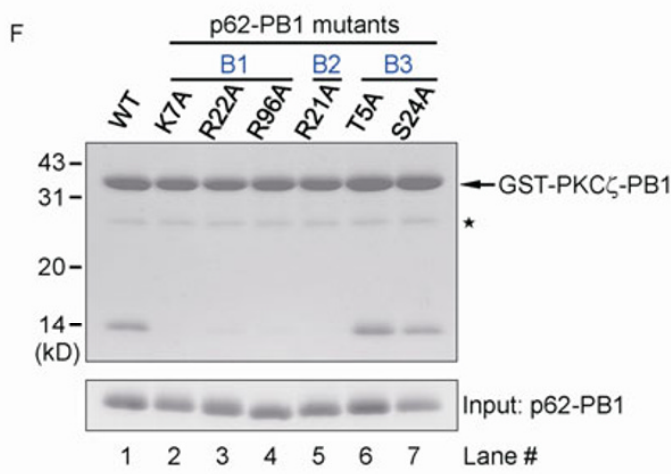

Figure 4 Interactions between p62-PB1 and PKC $\zeta-\mathrm{PB} 1$. A, Surface representations of p62-PB1 (left) and PKC $\zeta-\mathrm{PB} 1$ (right) showing their interfaces. The two surface representations, colored according to electrostatic potential (positive, blue; negative, red), are respectively oriented by a $90^{\circ}$ rotation around a vertical axis as indicated. B-D, Close-up views of interactions at the B1:A1 (B), B2:A2 (C) and B3:A3 (D) interfaces. The interacting residues of p62-PB1 and $\mathrm{PKC} \zeta-\mathrm{PB} 1$ are highlighted as orange and magenta sticks, respectively. Ion-pair and hydrogen-bonding interactions are indicated by black dashed lines. $\mathrm{E}$ and F, Effect of the point mutations of interacting residues on PKC $\zeta-P B 1(E)$ or p62-PB1 (F) on the formation of PKC $\zeta$-p62 complex. In the GST-mediated pull-down assay, the glutathione beads immobilized with GST-PKC $\zeta-P B 1$ were used to pull down p62-PB1. The top panels are the electrophoretic patterns after pull-down assays, and protein amounts of the GST-PKC $\zeta-P B 1$ (E) and p62-PB1 (F) mutants used are shown in the bottom panels, respectively. The asterisk indicates the GST contaminant. 
p62-PB1 completely ablated the formation of heterocomplex by disrupting the electrostatic interactions, while neither of the mutations at site B3 (T5A and S24A) interfered with its hetero-interaction with $\mathrm{PKC} \zeta-\mathrm{PB} 1$. These data demonstrate that the electrostatic interactions at the A1-B1 and A2-B2 interfaces are the major forces in the formation of a stable complex between PKC $\zeta-\mathrm{PB} 1$ and p62-PB1, while the hydrogen bonds between sites A3 and B3 exert an auxiliary function in specific recognition.

\subsection{The aPKC-PB1 domains belong to type I, rather than type I/II}

In human genome, there are at least 13 PB1-containing proteins that can form specific homo- or hetero-complexes to precisely modulate cellular signaling pathways, and a number of crystal/NMR structures of the homotypic PB1-PB1 complexes have been reported [24,32,34]. When these PB1 complexes were superimposed to our p62-PKC $\zeta$ complex, the relative orientations between two interacting PB1 domains in different complexes may change remarkably (Figure 5A). The two PB1 domains in the Par-6-PKCl (PDB ID: 1WMH) or MEKK2-MEK5 (2NPT) heterodimeric structures adopt almost identical relative positions as that in the
p62-PKC $\zeta$ complex, while the relative orientation between two p62-PB1 domains in its homodimeric structure (2KTR) displays moderate difference. Notably, the relative orientation in the complex of the $\mathrm{p} 67^{\text {phox }}$-PB1 and $\mathrm{p} 40^{\text {phox }}$-PB1 domains (1OEY) seems to be distinct, likely because of the additional interactions mediated by the $\mathrm{C}$-terminal tail of p40 phox - PB1. Nevertheless, all the homo- or heterocomplexes are formed in the front-to-back manner through interactions between the conserved basic surface and acidic OPCA motif.

Because of the presence of both the OPCA motif and an invariant Lys on strand $\beta 1$, the PB1 domains of aPKCs were thought to belong to the type I/II group (Figure $1 \mathrm{~B}$ ). Therefore, the aPKC-PB1 domains, similar to p62-PB1, were expected to mediate homo-oligomerization and/or interact with either other type I or type II PB1 domains. Although self-assembly has not been shown for the aPKC-PB1 domains, evidences showed that aPKC-PB1 can form complex with different types of PB1 domains from MEK5, Par-6 and p62-PB1, respectively $[18,31,32,35]$. However, the PB1 domains of both $\mathrm{PKC} \zeta$ and $\mathrm{PKC} \mathrm{C}$ do not form complex with the type I MEK5-PB1 in in vitro gel filtration and GSTmediated pull-down assays (data not shown), and they interact with the type II Par-6-PB1 and the type I/II p62-PB1
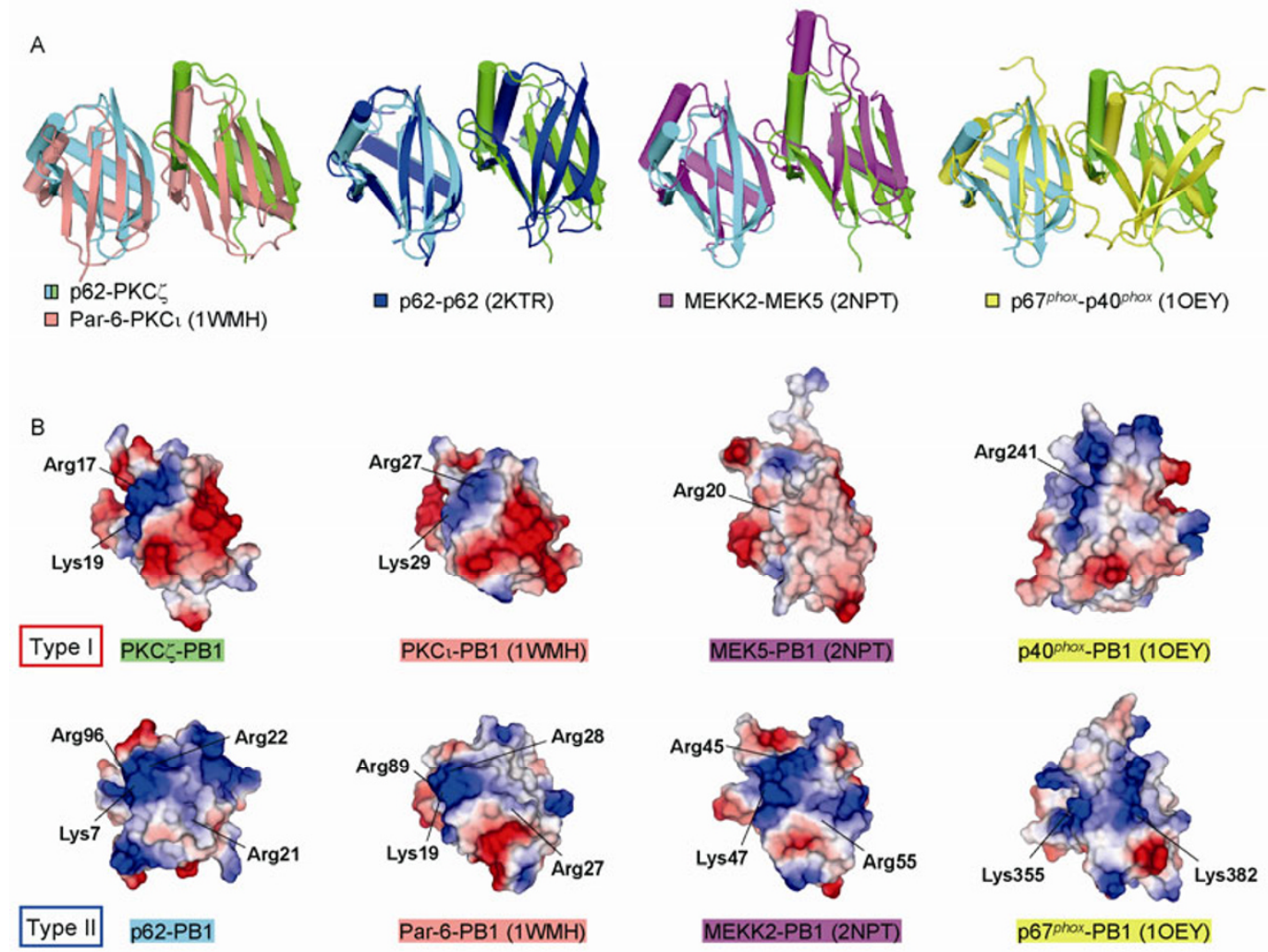

Figure 5 aPKC-PB1 belongs to type I. A, Superposition of p62-PKCל (cyan and green) with Par-6-PKC1 (salmon, PDB ID: 1WMH), p62-p62 (blue, 2KTR), MEKK2-MEK5 (magenta, 2NPT) or p67 $7^{\text {hox }}$-p40 phox (yellow, 1OEY). The PB1 domain in each complex that provides the basic surface for the homotypic interaction is used for superposition. B, Surface representations of the basic surfaces or the corresponding surfaces of indicated PB1 domains oriented the same as p62-PB1 in Figure 4A. The surface representations are colored by electrostatic potential, and the basic residues contributing to the positively charged regions are indicated. 
domains in almost identical mode through the acidic OPCA motif (Figure 5A). In addition, the sequences of both aPKC-PB1 domains are lack of several key basic residues that were identified in the reported PB1 complex structures (Figure 1B). These analyses indicate that aPKC-PB1 should belong to the type I group. On close inspection of the surface potential, we found that all the functional basic surface of the type II and type I/II PB1 domains present both the B1 and $\mathrm{B} 2$ sites (Figure 5B). In particular, the B1 site is unambiguously centered on the invariant Lys on strand $\beta 1$, while site B2 is formed by Lys or Arg from strand $\beta 2$ (p62, Par-6 and MEKK2/3) or helix $\alpha 1$ (p67 $7^{\text {phox }}$ ). By contrast, the corresponding surfaces on the type I PB1 domains from MEK5 and $\mathrm{p} 40^{\text {phox }}$ are essentially negatively charged (Figure $5 \mathrm{~B}$ ). Remarkably, the corresponding 'B2 sites' of two aPKC-PB1 domains are strikingly acidic, though their 'B1 sites' display the positive electrostatic patches. Our data (Figure 4F), together with previous reports, clearly suggest that the $\mathrm{B} 2$ site is indispensable for the PB1-PB1 homotypic interactions. Therefore, we believe that the presence of an acidic 'B2 site' on the basic surface would impede its interaction with the acidic OPCA motif, and that the PB1 domains of aPKCs should be classified into type I (Figure 1B).

\subsection{Cysteine modification of PKC -PB1 by ATM im- pedes its interaction with $\mathrm{p62}-\mathrm{PB} 1$}

The gold-containing compounds aurothioglucose (ATG) and aurothiomalate (ATM) in active clinical use for the treatment of rheumatoid arthritis are thiol-reactive agents capable of modifying cysteine residues [37]. These compounds have been shown to effectively modify $\mathrm{PKCl}$ and ablate its association with Par-6 [38-40]. Considering that $\mathrm{PKC} \zeta$ and $\mathrm{PKCl}$ are highly conserved in both sequence and structure, we examined the effect of ATM modification on the interaction between $\mathrm{PKC} \zeta$ and p62. We prepared the ATM-modified PKC $\zeta$-PB1 protein and assessed the binding affinity between p62 and $\mathrm{PKC} \zeta$ using isothermal titration calorimetry (ITC). As expected, the native $\mathrm{PKC} \zeta-\mathrm{PB} 1$ protein forms a stable complex with p62-PB1, with a dissociation constant $\left(K_{\mathrm{d}}\right)$ of $21.6 \pm 2.09 \mathrm{nmol} \mathrm{L} \mathrm{L}^{-1}$ that is comparable to the reported values for other PB1-PB1 assemblies $[30,32]$. On the contrary, the ATM-modified PKC $\zeta-\mathrm{PB} 1$ failed to bind to p62-PB1 (Figure 6A), suggesting that ATM modifies PKC $\zeta-\mathrm{PB} 1$ and impedes its interaction with p62-PB1.

ATM was suggested to selectively target a unique cysteine residue, Cys69, within the OPCA motif of PKC1-PB1 [38]. However, there are four cysteine residues in both aPKC-PB1 sequences, and these thiol groups are all exposed to solvent in their structures (Figures $1 \mathrm{~B}$ and $3 \mathrm{~A}$ ). To examine whether all Cys residues can be modified, we studied the modification kinetics of PKC $\zeta-P B 1$ by DTNB, a widely used reagent that reacts specifically with available thiol groups of proteins. Time course for the DTNB modi- fication of free thiol groups can be monitored spectrophotometrically (Figure 6B). When the native $\mathrm{PKC} \zeta-\mathrm{PB} 1$ protein $\left(1 \mu \mathrm{mol} \mathrm{L}{ }^{-1}\right)$ was treated with DTNB, approximately $4 \mu \mathrm{mol} \mathrm{L} \mathrm{L}^{-1}$ of free thiol groups were modified by DTNB, consistent with the structure observation; however, no free thiol group was detected for the ATM-modified PKC $\zeta-P B 1$. The results clearly suggest that ATM non-selectively blocks all four cysteine residues within the $\mathrm{PKC} \zeta$-PB1 domain.

Structurally, it is the steric effect caused by the modification of a specific cysteine, Cys68, on the interface of $\mathrm{PKC} \zeta-\mathrm{PB} 1$ that would inhibit its interaction with p62. We then generated a number of Cys68 mutations and examined their effect on the homotypic PB1-PB1 interaction between $\mathrm{PKC} \zeta$ and p62 in vitro (Figure 6C). Remarkably, mutating Cys68 to residues with bulky side chains (Tyr, Trp, Phe or Arg) led to complete loss of the PKC $\zeta-$ p62 interaction, whereas substitution by Val (or Ile, data not shown), the corresponding residue(s) in other PB1 domains, had little effect. These data, together with previous results [38], indicate that the conserved cysteine within the OPCA motif of aPKC-PB1 domains is the determinant for ATM inhibition of the interactions between aPKCs and other PB1-containing proteins with a functional basic surface.

ATM suppresses inflammation and retards bone erosion in arthritis and is capable of improving clinical conditions in a majority of patients, but the biological targets and the molecular mechanism of this drug are unclear [37,41,42]. The MAPK phosphatase-1, IкB kinase, and thioredoxin reductase have been shown to be the target of ATM to regulate $\mathrm{NF}-\kappa \mathrm{B}$ activation in different cell types, and the essential cysteine residues in their active sites have been proposed to be the ATM-modification sites $[37,42,43]$. ATM was reported to disrupt PKC1-Par-6 interaction and inhibit non-small cell lung cancer growth and/or kill prostate cancer cells, which renders ATM a promising anticancer drug target $[38-40,44]$. We demonstrate here that ATM disrupts, through a similar mechanism, the $\mathrm{p} 62-\mathrm{PKC} \zeta$ interaction that is required for the biological functions of $\mathrm{PKC} \zeta$ in $\mathrm{NF}-\kappa \mathrm{B}$ signaling $[15,16]$. Considering that dysfunction of $N F-\kappa B$ has been linked to inflammatory, cancer, improper immune development and many other diseases, our data shed light on the molecular mechanism of ATM as a promising drug target for inflammation, autoimmune and cancer treatments.

\subsection{PKC $\zeta-P B 1$ depolymerizes the p62-PB1 homo- oligomer}

As a well-defined type I/II PB1, p62-PB1 is characteristic of self-assembly in the same front-to-back manner through the two oppositely charged surfaces $[18,31,34]$. The thermodynamics of p62-PB1 self-association was analyzed by ITC, with a $K_{\mathrm{d}}$ value of $8.93 \pm 0.94 \mathrm{nmol} \mathrm{L}^{-1}$, which is slightly lower than that for the p62-PKC $\zeta$ heterodimer (Figure 7A). In the gel filtration assays, the wild-type p62-PB1 was elut- 

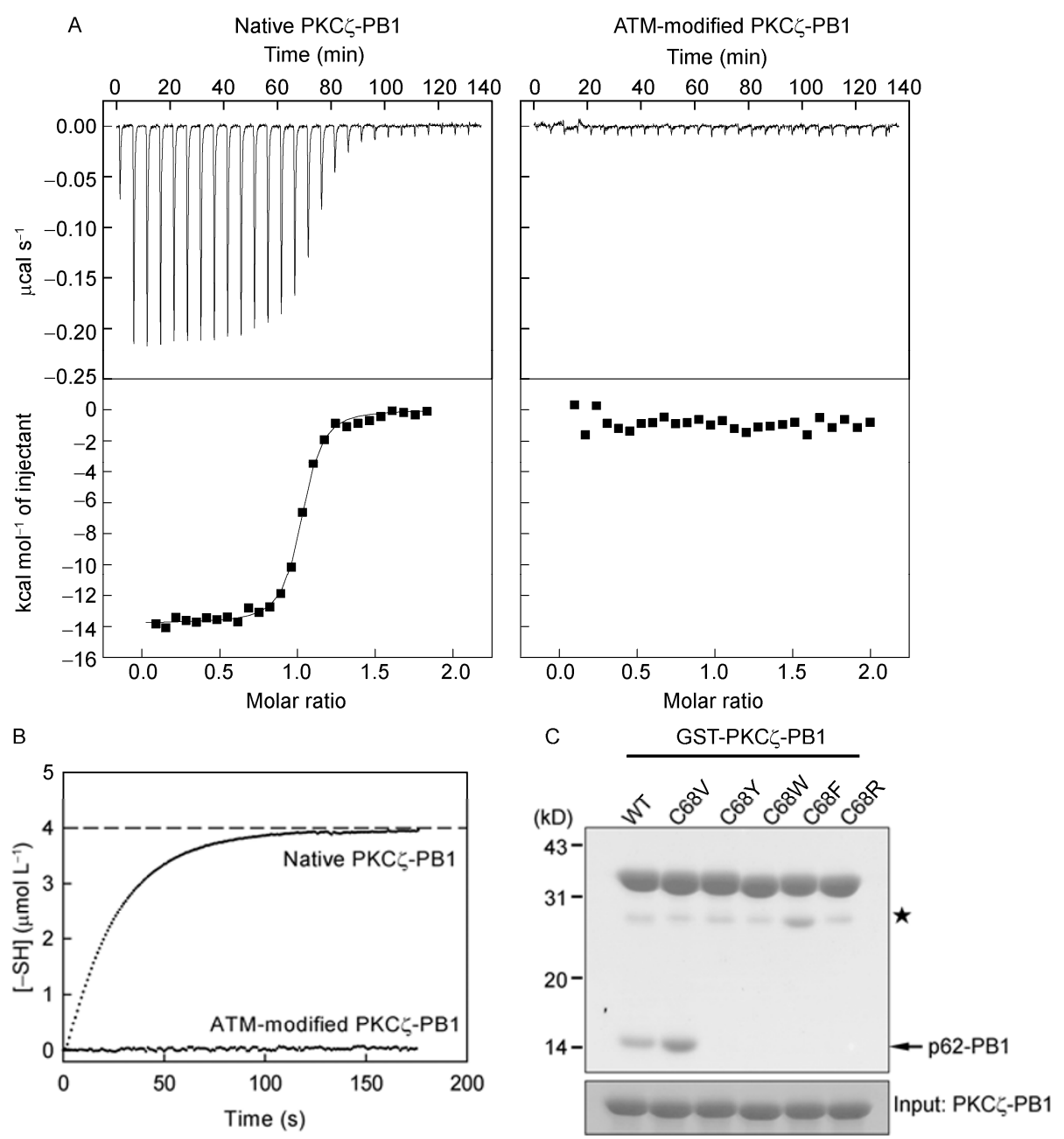

Figure 6 ATM-modified PKC $\zeta-\mathrm{PB} 1$ fails to interact with p62-PB1. A, Thermodynamic analysis of the interaction between PKC $\zeta-\mathrm{PB} 1$ and p62-PB1 by ITC. The top panels show heat release during titration of aliquots of p62-PB1AM into native (left) and ATM-modified (right) PKC $\zeta$-PB1, corrected for baseline drift, and the bottom panels show the corresponding integrated heat of binding. B, Modification of native and ATM-modified PKC $\zeta$-PB $1\left(1 \mu\right.$ mol L $\left.{ }^{-1}\right)$ by DTNB $\left(6.25 \mu \mathrm{mol} \mathrm{L}^{-1}\right)$. The modication process was monitored directly by absorbance measurements at $412 \mathrm{~nm}$. $-\mathrm{SH}$, reactive thiol group. C, Effect of

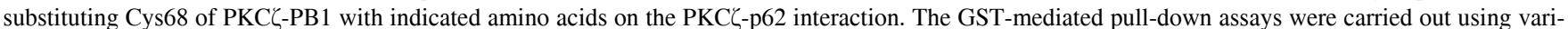
ous GST-PKC $-\mathrm{PB} 1$ mutants as indicated and p62-PB1AM.

ed in the void volume, consistent with its nature of highmolecular-weight homo-oligomers (Figure 7B). To assess the impact of $\mathrm{PKC} \zeta-\mathrm{PB} 1$ on oligomerization of the native p62-PB1, we coexpressed these two PB1 domains and found that the existence of $\mathrm{PKC} \zeta-\mathrm{PB} 1$ converted the high-molecular-weight p62-PB1 polymer to complexes of lower order (Figure 7B). Furthermore, we generated a complex between p62-PB1AM and p62-PB1BM to mimic the native p62-PB1 interaction, and its molecular weight was characterized to be $\sim 30 \mathrm{kD}$, consistent with the calculated molecular mass of a p62-PB1 dimer (Figure 7B and C). We carried out competition assays between this complex and the GST-tagged PKC $\zeta$-PB1, which can be distinguished on the size exclusion chromatography. Due to the presence of a dimeric GST tag, the retention time of GST-PKC $\zeta-P B 1$ corresponded to an apparent molecular weight of $\sim 70 \mathrm{kD}$, in reasonable agreement with its calculated dimeric molecular mass of $75 \mathrm{kD}$ (Figure $7 \mathrm{~B}$ and $\mathrm{C}$ ). When the mixture of GST-PKC $\zeta-P B 1$ and the p62-PB1 dimer was subjected to the gel filtration analysis, some of the p62-PB1AM proteins comigrated with $\mathrm{PKC} \zeta-\mathrm{PB} 1$, which leaves some p62$\mathrm{PB} 1 \mathrm{BM}$ proteins in the uncomplexed, monomeric state (Figure 7B and C). Notably, the GST-mediated PKC dimer likely forms a tetramer with two molecules of p62PB1AM, in agreement with our previous data of a $1: 1$ complex between the non-tagged PKC $\zeta_{-} \mathrm{PB} 1$ and p62PB1AM (Figure 2C). Together, these data demonstrate that PKC $\zeta-P B 1$ indeed disrupts the p62-PB1 homo-oligomer and concomitantly forms a front-to-back complex with p62-PB1, through interactions between the acidic OPCA motif of PKC $\zeta-P B 1$ and the basic surface of p62-PB1. Evidences have indicated that loss of p62 homo-oligomerization affects its cellular function, such as triggering the TRAF6$N F-\kappa B$ pathway [20]. Therefore, the depolymerization of 

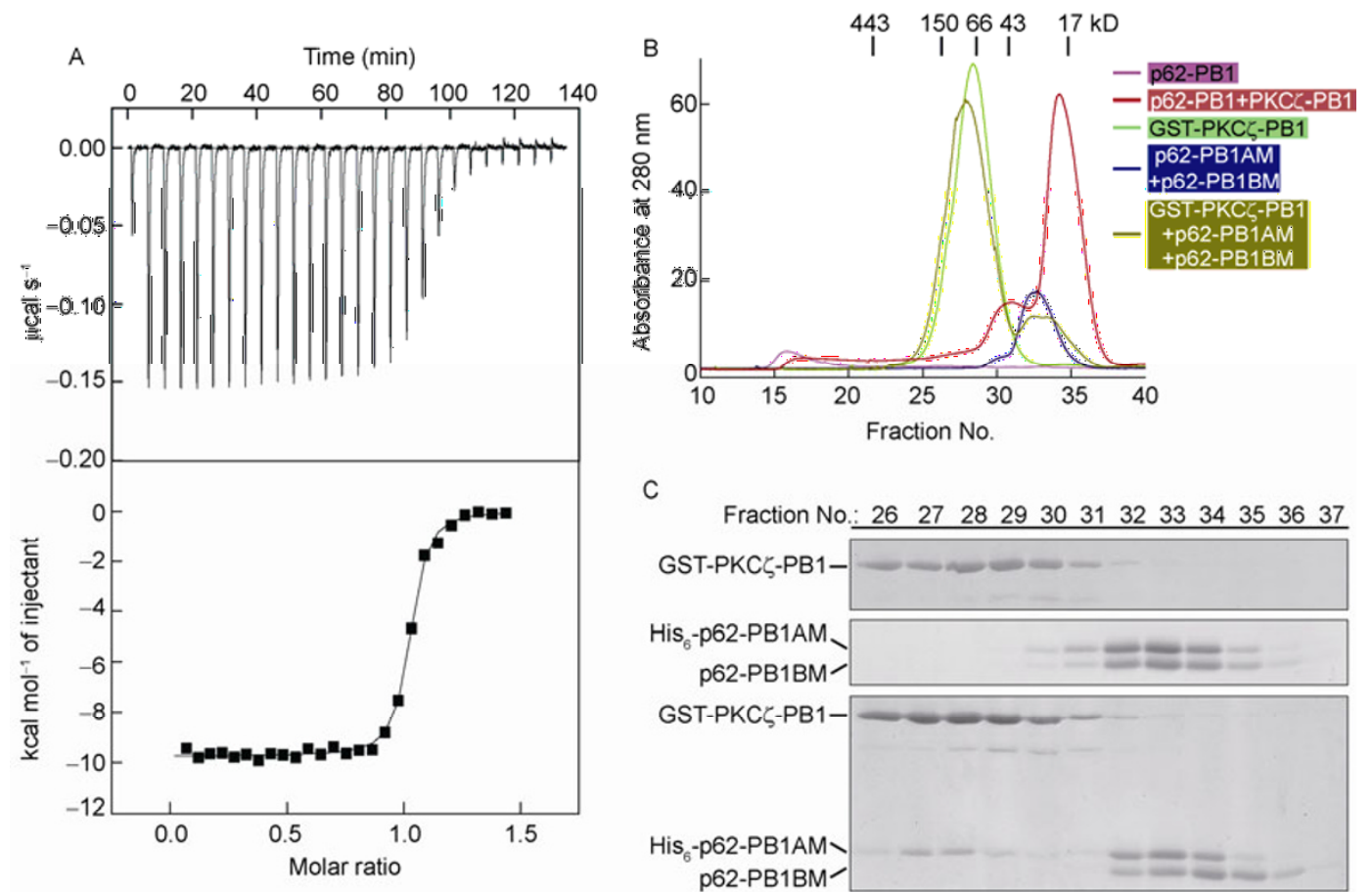

Figure 7 PKC $\zeta-\mathrm{PB} 1$ depolymerizes p62-PB1 homo-oligomer. A, Thermodynamic analysis of the p62 homo-oligomerization by ITC. The p62-PB1AM protein was titrated into a solution of p62-PB1BM. B, PKC $\zeta$ converts the high-molecular-weight homo-assembly of p62 to a lower order in gel filtration analysis. C, PKC $\zeta-\mathrm{PB} 1$ disrupts the p62-PB1 homo-complex. GST-tagged PKC $\zeta-\mathrm{PB} 1$ was incubated with the pre-formed homo-complex of His6-p62$\mathrm{PB} 1 \mathrm{AM}$ and $\mathrm{p} 62-\mathrm{PB} 1 \mathrm{BM}$, and the mixture was analyzed by size exclusion chromatography.

p62 homo-assembly by $\mathrm{PKC} \zeta$ might affect the formation and efficiency of the p62-TRAF6 signaling hubs that are critical for NF- $\kappa \mathrm{B}$ activation. Further investigations are required to elucidate the molecular mechanisms.

In summary, we solved the crystal structure of $\mathrm{PKC} \zeta$ PB1 in complex with the monomeric p62-PB1AM mutant, which affirms the front-to-back interaction between the acidic OPCA motif of one PB1 domain and the basic surface from another PB1 domain (Figures 3 and 4). Notably, we identified an additional A3-B3 interface between PKC $\zeta$ and p62 that may endow the specificity. Our detailed structural analyses suggest that the PB1 domains of both aPKC isoforms belong to the type I group, but not type I/II (Figure 5). In addition, the gold-containing compound ATM can modify the conserved cysteine residue within the OPCA motif of the aPKC isoforms, which disrupts the interactions between p62 and $\mathrm{PKC} \zeta$ and might thus down-regulate the $\mathrm{NF}-\kappa \mathrm{B}$ signaling (Figure 6). Interestingly, we also found that $\mathrm{PKC} \zeta$-PB1 can attenuate the formation of highmolecular-weight p62-PB1 homo-oligomers, which might regulate the polyubiquitination of TRAF6 and subsequent activation of NF- $\kappa \mathrm{B}$ (Figure 7). Taken together, our structural and biochemical results provide the basis for developing inhibitors of the NF- $\mathrm{KB}$ pathway, particularly the thiol-reactive reagents that target the essential cysteine residues of aPKC isoforms.
Crystallographic data were collected at Shanghai Synchrotron Radiation Facility (SSRF) beamline 17U. This work was supported in part by the National Natural Science Foundation of China (31070643 and 31130062) and Tsinghua University (20121080028).

1 Steinberg SF. Structural basis of protein kinase C isoform function. Physiol Rev, 2008, 88: 1341-1378

2 Roffey J, Rosse C, Linch M, Hibbert A, McDonald NQ, Parker PJ. Protein kinase C intervention-the state of play. Curr Opin Cell Biol, 2009, 21: 268-279

3 Mochly-Rosen D, Das K, Grimes KV. Protein kinase C, an elusive therapeutic target? Nat Rev Drug Discov, 2012, 11: 937-957

4 Newton AC. Protein kinase C: structural and spatial regulation by phosphorylation, cofactors, and macromolecular interactions. Chem Rev, 2001, 101: 2353-2364

5 Hirai $\mathrm{T}$, Chida K. Protein kinase $\mathrm{C} \zeta(\mathrm{PKC} \zeta)$ : activation mechanisms and cellular functions. J Biochem, 2003, 133: 1-7

6 Suzuki A, Akimoto K, Ohno S. Protein kinase C $\lambda / \mathrm{l}(\mathrm{PKC} \lambda / \mathrm{l})$ : a PKC isotype essential for the development of multicellular organisms. J Biochem, 2003, 133: 9-16

7 Pawson T, Nash P. Assembly of cell regulatory systems through protein interaction domains. Science, 2003, 300: 445-452

8 Sumimoto H, Kamakura S, Ito T. Structure and function of the PB1 domain, a protein interaction module conserved in animals, fungi, amoebas, and plants. Sci STKE, 2007, 2007: re6

9 Moscat J, Diaz-Meco MT. The atypical protein kinase Cs. Functional specificity mediated by specific protein adapters. EMBO Rep, 2000, 1: $399-403$

10 Moscat J, Diaz-Meco MT, Albert A, Campuzano S. Cell signaling and function organized by PB1 domain interactions. Mol Cell, 2006, 23: 631-640

11 Puls A, Schmidt S, Grawe F, Stabel S. Interaction of protein kinase C $\zeta$ with ZIP, a novel protein kinase C-binding protein. Proc Natl Acad Sci USA, 1997, 94: 6191-6196 
12 Sanchez P, De Carcer G, Sandoval IV, Moscat J, Diaz-Meco MT. Localization of atypical protein kinase $\mathrm{C}$ isoforms into lysosome-targeted endosomes through interaction with p62. Mol Cell Biol, 1998, 18: 3069-3080

13 Moscat J, Diaz-Meco MT. p62 at the crossroads of autophagy, apoptosis, and cancer. Cell, 2009, 137: 1001-1004

14 Moscat J, Diaz-Meco MT. p62: a versatile multitasker takes on cancer. Trends Biochem Sci, 2012, 37: 230-236

15 Sanz L, Sanchez P, Lallena MJ, Diaz-Meco MT, Moscat J. The interaction of $\mathrm{p} 62$ with RIP links the atypical PKCs to NF- $\mathrm{NB}$ activation. EMBO J, 1999, 18: 3044-3053

16 Sanz L, Diaz-Meco MT, Nakano H, Moscat J. The atypical PKC-interacting protein p62 channels NF- $\kappa B$ activation by the IL-1-TRAF6 pathway. EMBO J, 2000, 19: 1576-1586

17 Diaz-Meco M, Moscat J. The atypical PKCs in inflammation: NF- $\kappa B$ and beyond. Immunol Rev, 2012, 246: 154-167

18 Lamark T, Perander M, Outzen H, Kristiansen K, Øvervatn A, Michaelsen E, Bjørkøy G, Johansen T. Interaction codes within the family of mammalian Phox and Bem1p domain-containing proteins. $J$ Biol Chem, 2003, 278: 34568-34581

19 Bjørkøy G, Lamark T, Brech A, Outzen H, Perander M, Øvervatn A, Stenmark H, Johansen T. p62/SQSTM1 forms protein aggregates degraded by autophagy and has a protective effect on huntingtin-induced cell death. J Cell Biol, 2005, 171: 603-614

20 Wooten MW, Geetha T, Seibenhener ML, Babu JR, Diaz-Meco MT, Moscat J. The p62 scaffold regulates nerve growth factor-induced $\mathrm{NF}-\kappa \mathrm{B}$ activation by influencing TRAF6 polyubiquitination. J Biol Chem, 2005, 280: 35625-35629

21 Duran A, Linares JF, Galvez AS, Wikenheiser K, Flores JM, Diaz-Meco MT, Moscat J. The signaling adaptor p62 is an important

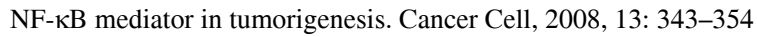

22 Otwinowski Z, Minor W. Processing of X-ray diffraction data collected in oscillation mode. Methods Enzymol, 1997, 276: 307-326

23 McCoy AJ, Grosse-Kunstleve RW, Adams PD, Winn MD, Storoni LC, Read RJ. Phaser crystallographic software. J Appl Crystallogr, 2007, 40: 658-674

24 Hirano Y, Yoshinaga S, Takeya R, Suzuki NN, Horiuchi M, Kohjima M, Sumimoto H, Inagaki F. Structure of a cell polarity regulator, a complex between atypical PKC and Par6 PB1 domains. J Biol Chem, 2005, 280: 9653-9661

25 Adams PD, Afonine PV, Bunkoczi G, Chen VB, Davis IW, Echols N, Headd JJ, Hung LW, Kapral GJ, Grosse-Kunstleve RW, McCoy AJ, Moriarty NW, Oeffner R, Read RJ, Richardson DC, Richardson JS, Terwilliger TC, Zwart PH. PHENIX: a comprehensive Python-based system for macromolecular structure solution. Acta Crystallogr D Biol Crystallogr, 2010, 66: 213-221

26 Emsley P, Lohkamp B, Scott WG, Cowtan K. Features and development of Coot. Acta Crystallogr D Biol Crystallogr, 2010, 66: 486-501

27 Laskowski RA, MacArthur MW, Moss DS, Thornton JM. PROCHECK: a program to check the stereochemical quality of protein structures. J Appl Crystallogr, 1993, 26: 283-291

28 Dynon MK, Jago GR, Davidson BE, Gething MJH. The subunit structure of lactate dehydrogenase from Streptococcus cremoris US3. Eur J Biochem, 1972, 30: 348-353

29 Yoshinaga S, Kohjima M, Ogura K, Yokochi M, Takeya R, Ito T,
Sumimoto H, Inagaki F. The PB1 domain and the PC motifcontaining region are structurally similar protein binding modules. EMBO J, 2003, 22: 4888-4897

30 Hu Q, Shen W, Huang H, Liu J, Zhang J, Huang X, Wu J, Shi Y. Insight into the binding properties of MEKK3 PB1 to MEK5 PB1 from its solution structure. Biochemistry, 2007, 46: 13478-13489

31 Noda Y, Kohjima M, Izaki T, Ota K, Yoshinaga S, Inagaki F, Ito T, Sumimoto H. Molecular recognition in dimerization between PB1 domains. J Biol Chem, 2003, 278: 43516-43524

32 Wilson MI, Gill DJ, Perisic O, Quinn MT, Williams RL. PB1 domain-mediated heterodimerization in NADPH oxidase and signaling complexes of atypical protein kinase C with Par6 and p62. Mol Cell, 2003, 12: 39-50

33 Saio T, Yokochi M, Inagaki F. The NMR structure of the p62 PB1 domain, a key protein in autophagy and NF- $\kappa B$ signaling pathway. $\mathrm{J}$ Biomol NMR, 2009, 45: 335-341

34 Saio T, Yokochi M, Kumeta H, Inagaki F. PCS-based structure determination of protein-protein complexes. J Biomol NMR, 2010, 46: 271-280

35 Hirano Y, Yoshinaga S, Ogura K, Yokochi M, Noda Y, Sumimoto H, Inagaki F. Solution structure of atypical protein kinase C PB1 domain and its mode of interaction with ZIP/p62 and MEK5. J Biol Chem, 2004, 279: 31883-31890

36 Terasawa $\mathrm{H}$, Noda $\mathrm{Y}$, Ito $\mathrm{T}$, Hatanaka H, Ichikawa S, Ogura K, Sumimoto H, Inagaki F. Structure and ligand recognition of the PB1 domain: a novel protein module binding to the PC motif. EMBO J, 2001, 20: 3947-3956

37 Jeon KI, Jeong JY, Jue DM. Thiol-reactive metal compounds inhibit NF- $\kappa$ B activation by blocking I $\mathrm{B}$ kinase. J Immunol, 2000, 164: 5981-5989

38 Erdogan E, Lamark T, Stallings-Mann M, Jamieson L, Pellechia M, Thompson EA, Johansen T, Fields AP. Aurothiomalate inhibits transformed growth by targeting the $\mathrm{PB} 1$ domain of protein kinase $\mathrm{Cl}$. $\mathrm{J}$ Biol Chem, 2006, 281: 28450-28459

39 Stallings-Mann M, Jamieson L, Regala RP, Weems C, Murray NR, Fields AP. A novel small-molecule inhibitor of protein kinase $\mathrm{Cl}$ blocks transformed growth of non-small-cell lung cancer cells. Cancer Res, 2006, 66: 1767-1774

40 Fields AP, Regala RP. Protein kinase $\mathrm{Cl}$ : Human oncogene, prognostic marker and therapeutic target. Pharmacol Res, 2007, 55: 487-497

41 Gunatilleke S, de Oliveira C, McCammon J, Barrios A. Inhibition of cathepsin $\mathrm{B}$ by $\mathrm{Au}(\mathrm{I})$ complexes: a kinetic and computational study. J Biol Inorg Chem, 2008, 13: 555-561

42 Nieminen R, Korhonen R, Moilanen T, Clark AR, Moilanen E. Aurothiomalate inhibits cyclooxygenase 2 , matrix metalloproteinase 3 , and interleukin- 6 expression in chondrocytes by increasing MAPK phosphatase 1 expression and decreasing p38 phosphorylation: MAPK phosphatase 1 as a novel target for antirheumatic drugs. Arthritis Rheum, 2010, 62: 1650-1659

43 Sakurai A, Yuasa K, Shoji Y, Himeno S, Tsujimoto M, Kunimoto M, Imura N, Hara S. Overexpression of thioredoxin reductase 1 regulates NF- $\kappa$ B activation. J Cell Physiol, 2004, 198: 22-30

44 Trani M, Sorrentino A, Busch C, Landström M. Pro-apoptotic effect of aurothiomalate in prostate cancer cells. Cell Cycle, 2009, 8: 306-313

Open Access This article is distributed under the terms of the Creative Commons Attribution License which permits any use, distribution, and reproduction in any medium, provided the original author(s) and source are credited. 